\title{
The Solid Phase Distribution and Bioaccessibility of Arsenic, Chromium, and Nickel in Natural Ironstone Soils in the UK
}

\author{
Joanna Wragg, ${ }^{1}$ Mark Cave, ${ }^{1}$ and Sean Gregory ${ }^{2}$ \\ ${ }^{1}$ British Geological Survey, Keyworth, Nottingham NG12 5GG, UK \\ ${ }^{2}$ Cherwell District Council 2013 Bodicote House, Bodicote, Banbury OX15 4AA, UK
}

Correspondence should be addressed to Joanna Wragg; jwrag@bgs.ac.uk

Received 26 July 2013; Revised 19 December 2013; Accepted 27 January 2014; Published 5 March 2014

Academic Editor: Balwant Singh

Copyright (C) 2014 Joanna Wragg et al. This is an open access article distributed under the Creative Commons Attribution License, which permits unrestricted use, distribution, and reproduction in any medium, provided the original work is properly cited.

\begin{abstract}
Thirty soil samples (12 residential gardens and 18 allotments) were collected from the Cherwell District of north Oxfordshire in south-central England. The underlying parent geology of the area is dominated by Jurassic ironstone. The samples were analysed for their total contents of As, Cr, and Ni by X-ray fluorescence spectroscopy and for the bioaccessible fractions of these elements using a physiologically based extraction test. Four soils (two residential soils and two allotment soils) were chosen for further determination of their element solid phase distribution. The study showed that whilst total concentrations of As, $\mathrm{Cr}$, and $\mathrm{Ni}$ are elevated due to the soil parent material, the bioaccessibility test showed that only a small proportion of the total concentration is available for absorption into the human body $(<15 \%)$. The sequential extraction test showed that the nonmobile forms of the elements are strongly sorbed on to iron oxides. Parent material geology has a significant effect on the total element concentrations and the bioaccessibility of potentially harmful element (PHE). Land use does not show such a large effect but the allotment bioaccessibility data show a bigger spread and possibly higher values for As and Cr which may be due to agronomic (cultivation) practices such as addition of fertilisers and organic matter.
\end{abstract}

\section{Introduction}

The mobility of potentially harmful elements (PHEs) present in soils is influenced by chemical reactions and both physical and biological processes occurring within soils. Commonly encountered soil PHEs include arsenic (As), chromium (Cr), and nickel $(\mathrm{Ni})$, all of which can be harmful to human health via oral ingestion, inhalation, or dermal uptake $[1,2]$. Naturally occurring soil PHE in the environment results from weathering of parent rock material, with As being associated with igneous rocks, but more commonly the highest concentrations tend to be observed in sedimentary rocks (e.g., sandstones, shales, and mudstones) and in heavily sulphidic mineralised areas [3]. Natural As enrichment of a parent material, such as a sedimentary ironstone, is thought to be due to the abundance of iron-bearing minerals, especially iron oxyhydroxides, as these have a high affinity for As [4]. Soil Cr is abundant in basic, ultrabasic, and igneous rocks and shales and in topsoils mirrors the clay content [5]. Weathering of basic igneous rocks results in a large proportion of soil
$\mathrm{Ni}$, although lower concentrations are found in association with sedimentary rocks including shales, clays, limestones, and sandstones $[3,6]$. All three elements of interest in this study are found, often colocated, in a broad band of clay that includes the Jurassic ironstones and stretches from Bristol to the east of Nottingham and up to Scunthorpe [5]. Industrial activity in the UK, often related to the mining and smelting of mineralised PHE, has resulted in elevated soil concentrations of these elements in urban areas ranging from Swansea in south Wales to Derby and Nottingham in the Midlands and further the industrial belt of Yorkshire and Lancashire [7].

Mean soil element concentrations for England and Wales have recently been published in the "Advanced soil geochemical atlas of England and Wales" [5]. This document presents distribution maps for a total of 53 elements, which include 17 from the original study by the National Soil Inventory (NSI) and the remainder were generated by reanalysis of the original collected soil samples. The ranges of soil concentrations reported were $0-820 \mathrm{mg} \mathrm{kg}^{-1}, 5.1-1141 \mathrm{mg} \mathrm{kg}^{-1}$, and $0.26-459 \mathrm{mg} \mathrm{kg}^{-1}$ for $\mathrm{As}, \mathrm{Cr}$, and $\mathrm{Ni}$, respectively. The mean 
concentrations of As, $\mathrm{Cr}$, and Ni were $20 \mathrm{mg} \mathrm{kg}^{-1}, 68 \mathrm{mg} \mathrm{kg}^{-1}$, and $23 \mathrm{mg} \mathrm{kg}^{-1}$.

A number of researchers have shown the association of PHEs such as As, Cr, and Ni with Jurassic ironstone derived soils, in particular the Frodingham and Claxby ironstones [8-11]. Soil contaminant mobility research [8-11] has shown that the presence of PHEs in soils may not be mobile and hence does not present a risk to human health. Such studies have linked contaminant mobility, via the measurement of in vitro bioaccessibility, to the source apportionment of soil contaminants and/or properties of soils [12], where bioaccessibility is defined as the fraction of a contaminant that is soluble in the gastrointestinal environment and is available for absorption [13]. To date, a large proportion of this research has focussed on As, as this PHE is found to be a widespread naturally occurring element in UK soils and is associated with the Jurassic ironstone geology from areas such as Lincolnshire and Northamptonshire [10,11, 14]. But there is little work available detailing studies on other PHE such as $\mathrm{Cr}$ and $\mathrm{Ni}$ from ironstones from other areas of the UK. The area around the town of Banbury in the UK shows particularly elevated concentrations of $\mathrm{As}, \mathrm{Cr}$, and $\mathrm{Ni}$ compared to the surrounding areas [5]. The purpose of this work was to be the first study to assess the potential availability of $\mathrm{As}, \mathrm{Cr}$, and $\mathrm{Ni}$ present in ironstone derived soil samples from the Cherwell District, (Oxfordshire, UK) via the oral ingestion exposure route using a combination of geochemical tests: sequential extraction to identify the fractionation of the PHE within the geochemical components that make up the soil and in vitro bioaccessibility measurements to identify which components are the source(s) of the bioaccessible fraction.

\section{Materials and Methods}

All reagents were of analytical grade or better. Reagents for the analysis of extracts and digests were supplied by Merck and all reagents used for the PBET extraction were supplied by Sigma-Aldrich Ltd.

2.1. Sample Locations, Collection, and Preparation. A total of 30 soil samples were collected from seven locations across the Cherwell District of north Oxfordshire in south central England in July 2008 (Table 1). The underlying parent geology of the area is dominated by the Northampton Sand Formation [15]. The samples were stratified by underlying geology (Lias $n=18$ or Inferior Oolite Group $n=12$ ), by location, and by the type of site from which they were collected (residential garden $(n=12)$ or allotment $(n=18))$, shown in Figure 1. Samples were collected for the assessment of the potential human exposure to soil contamination via the ingestion pathway according to the standard British Geological Survey (BGS) approach for geochemical surveying work, collecting composite of material from hand auger flights taken from five holes of $0-15 \mathrm{~cm}$ depth [16]. For this work the support area was one square meter. The composite soil materials were stored in Kraft paper bags and uniquely labelled with the date and the GPS coordinates of the sample location. After collection, the samples were dried at $35 \pm 2^{\circ} \mathrm{C}$ on metal trays

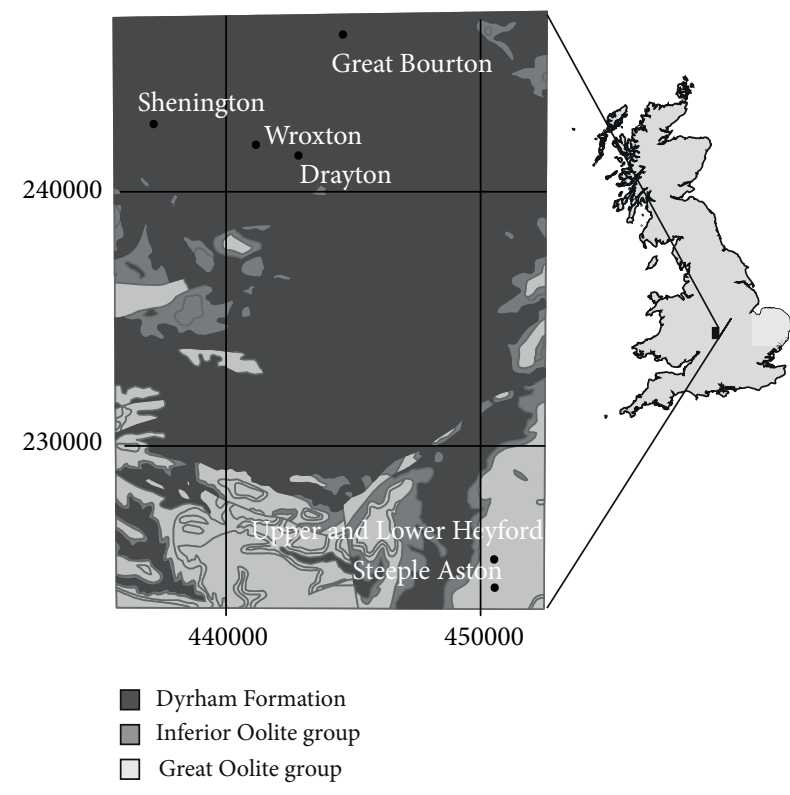

FIgURE 1: Local geology for the study site.

for at least 12 hours until they were visually dry, at which time each sample was gently disaggregated, to ensure the breakage of aggregates but retention of clasts, and sieved to extract the $<250 \mu \mathrm{m}$ fraction, using a nylon sieve mesh. This fraction is the upper bound of size fraction which is considered to adhere to the hands of the "at risk" receptor (children) considered in this study [17].

2.2. Total and Bioaccessible As, Cr, and Ni Extractions. Total $\mathrm{As}, \mathrm{Cr}$, and $\mathrm{Ni}$ were determined on a pressed powder pellet by Phillips wavelength dispersive WD-XRF, fitted with automatic sample changer, $60 \mathrm{kV}$ generator, and controlled by dedicated PC running PANalytical Super XRF software. The pressed powder pellets were prepared by grinding $12.0 \mathrm{~g}$ of the $<250 \mu \mathrm{m}$ soil material and $3.00 \mathrm{~g}$ of binder (EMU120FD, a styrene copolymer, and Ceridust 3620, a micronised polyethylene wax in a ratio of $9: 1$ ) in an agate planetary ball mill for 30 minutes followed by pressing into $40 \mathrm{~mm}$ diameter pellets at a 25 ton load. The instrument was calibrated using $1000 \mathrm{mg} \mathrm{kg}^{-1}$ single element standards in a silica matrix; background factors, where applicable, were calculated by angular difference or from regression values from "high purity" oxide blanks and line overlap factors were calculated from high concentration, multielement standards of the interfering analyte [18]. Uncertainties on the XRF data are $\pm 10 \%$.

A physiologically based extraction test (PBET), a modified version of that first described by Ruby et al. [19], was applied to the test soils to determine the proportion of $\mathrm{As}, \mathrm{Cr}$, and $\mathrm{Ni}$ that may be available for uptake via accidental ingestion. The PBET utilised was the BGS PBET, which has been previously fully described by Cave et al. [9], Palumbo-Roe et al. [10], and Wragg et al. [11], but which, in essence, is a two stage sequential extraction that simulates the physicochemical gastrointestinal human environment. 


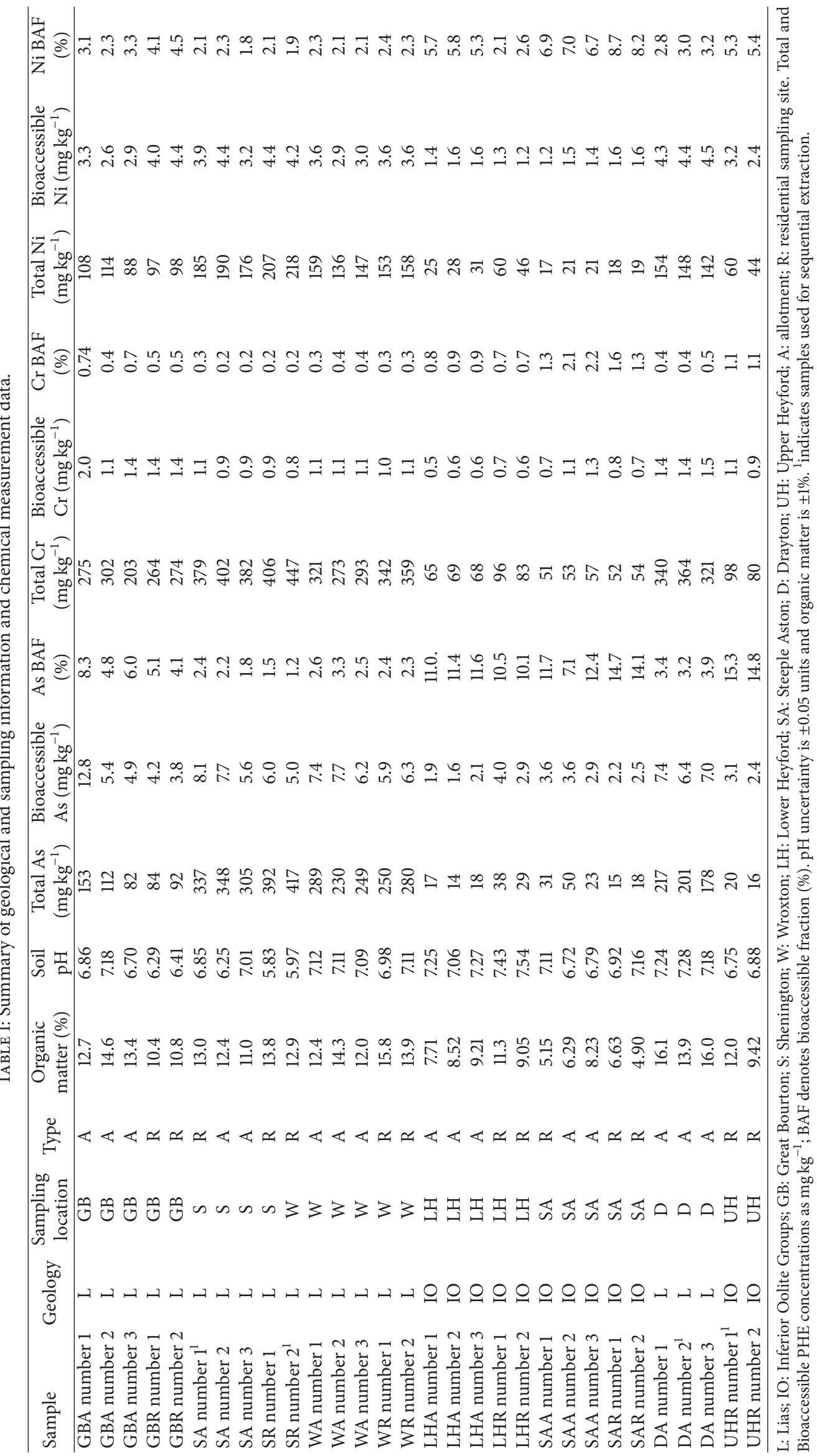


Each soil sample $(1 \mathrm{~g})$ was incubated at body temperature $\left(37^{\circ} \mathrm{C}\right)$ in an end-over-end rotator at $30 \mathrm{rpm}$ with $100 \mathrm{~mL}$ of simulated gastric solution $(1.25 \mathrm{~g}$ pepsin, $0.50 \mathrm{~g}$ sodium malate, $0.50 \mathrm{~g}$ sodium citrate, $420 \mu \mathrm{L}$ lactic acid, and $500 \mu \mathrm{L}$ acetic acid made up to $1 \mathrm{~L}$ with freshly prepared deionised water, adjusted to $\mathrm{pH} 2.5$ with concentrated $\mathrm{HCl}$ ) for one hour to simulate stomach conditions in the fasted state. After a 1 hour incubation period, a $5 \mathrm{~mL}$ sample was collected, via disposable syringe, and the sample filtered through a $0.45 \mu \mathrm{m}$ cellulose acetate syringe filter. To ensure that the solid: solution ratio was maintained, the filter was reversed and backflushed with a fresh $5 \mathrm{~mL}$ aliquot of gastric solution, thereby returning both the original volume of fluid and mass of solid. To simulate the small intestine, the conditions in each extraction vessel were then altered by titration against saturated $\mathrm{NaHCO}_{3}$ until a $\mathrm{pH}$ of 7.0 was obtained and the addition of $175 \mathrm{mg}$ bile salts and $50 \mathrm{mg}$ pancreatin. These conditions were maintained at $37^{\circ} \mathrm{C}$ for 4 hours. After an initial 2-hour period under small intestinal conditions, a $5 \mathrm{~mL}$ sample was collected via disposable syringe and cellulose acetate syringe filter and then again after 2 hours (4 hours in total) to complete the extraction. All samples were stored for analysis by Inductively Coupled Plasma Atomic Emission Spectrometry (ICP-AES) at $0-8^{\circ} \mathrm{C}$. Uncertainties of the PBET method are $\pm 15 \%$.

2.3. Solid Phase Distribution of As, Cr, and Ni. Four soils (two residential soils and two allotment soils), with total $\mathrm{As}, \mathrm{Cr}$, and $\mathrm{Ni}$ concentrations covering the range found in in all soil samples, were chosen for further determination of their PHE solid phase distribution. The solid phase distributions of these elements were determined by applying a nonspecific sequential extraction to the soils, known as the Chemometric Identification of Substrates and Element Distributions (CISED). The methodology, developed by Cave et al. [20], applied increasing concentrations of aqua regia to the solid material under investigation, which was supported on a $0.45 \mu \mathrm{m}$ polytetrafluoroethylene (PTFE) membrane filter tube insert housed inside a "Whatman Vectaspin 20" centrifuge tube. $10 \mathrm{~mL}$ of the nonspecific reagent was added, via pipette, to a $2 \mathrm{~g}$ aliquot of the test material and the extraction vessel was centrifuged at $1034 \mathrm{G}$ for 10 minutes, and the extract was removed and stored in a clean, dry, uniquely labelled $16.5 \mathrm{~mL}$ screw top polypropylene conical tube and stored at $0-8^{\circ} \mathrm{C}$ prior to analysis by ICP-AES. The process was repeated sequentially until 14 extracts for each solid material were produced. Each reagent was applied to the soil in duplicate. The extractants applied were deionised water followed by $0.01,0.05,0.10,0.50,1.00$, and $5.00 \mathrm{M}$ aqua regia.

2.4. Analysis of Bioaccessible and CISED. All extracted elements of interest, As, $\mathrm{Cr}$, and $\mathrm{Ni}$ for the PBET solutions and the major and trace cations ( $\mathrm{Al}, \mathrm{As}, \mathrm{B}, \mathrm{Ba}, \mathrm{Ca}, \mathrm{Cd}, \mathrm{Co}, \mathrm{Cr}, \mathrm{Cu}$, $\mathrm{Fe}, \mathrm{K}, \mathrm{Li}, \mathrm{Mg}, \mathrm{Mn}, \mathrm{Na}, \mathrm{Ni}, \mathrm{P}, \mathrm{Pb}, \mathrm{S}, \mathrm{Si}, \mathrm{Sr}, \mathrm{V}$, and $\mathrm{Zn}$ ) of interest in the CISED extracts were determined directly by a Varian Vista AX CCD simultaneous instrument with dedicated SPS5 autosampler and PC running ICP Expert Version 3.1b as supplied by the manufacturer. All instrument operating conditions have been previously reported [21, 22]. Instrument calibration was carried out using a series of a minimum of four mixed element matrix matched standards, covering a linear range up to $10 \mathrm{mg} \mathrm{L}^{-1}$ for $\mathrm{Al}, \mathrm{As}, \mathrm{B}, \mathrm{Ba}, \mathrm{Cd}, \mathrm{Co}, \mathrm{Cr}, \mathrm{Cu}$, $\mathrm{Li}, \mathrm{Ni}, \mathrm{P}, \mathrm{Pb}, \mathrm{Si}, \mathrm{Sr}, \mathrm{V}$, and $\mathrm{Zn} ; 50 \mathrm{mg} \mathrm{L}^{-1}$ for $\mathrm{K} ; 100 \mathrm{mg} \mathrm{L}^{-1}$ for $\mathrm{Fe}, \mathrm{Mn}$, and $\mathrm{S} ; 500 \mathrm{mg} \mathrm{L}^{-1}$ for $\mathrm{Mg}$ and $\mathrm{Ca}$; and $0-1000 \mathrm{mg} \mathrm{L}^{-1}$ for Na. For each sample type, a solution of $1 \% \mathrm{CsCl}_{2}$ was introduced into the sample introduction stream to increase the linear range of the calibration, therefore reducing the number of analytical dilutions required. All reported measurements, in $\mathrm{mg} \mathrm{L}^{-1}$, are based on the average of three tensecond replicate analyses. All element concentrations quoted have been converted into $\mathrm{mg} \mathrm{kg}^{-1}$ extracted from the solid matrix and the PBET value used for further interpretation is the highest value from either the stomach or one of the two intestinal compartments.

\subsection{Statistical Analysis and Modelling of the CISED Extraction} Data. Data processing of the ICP-AES analysis of the CISED extraction data was carried out using a modified version of the original self-modelling mixture resolution (SMMR) method described by Cave et al. [20], using the Matlab $\odot$ programming language. Full details of the modifications and their validation have been described by Cave [23]. Data processing was carried out to determine the number of soil components or substrates in each test material, the composition of the identified components, and the distribution of PHE between of the identified components. Previous applications of the methodology to soils with elevated PHE concentrations derived from Jurassic ironstone formations and mineralised geologies have been reported by Cave et al. [9], Palumbo-Roe et al. [10], Wragg [22], and Wragg et al. [11]. Four samples selected on the basis of being representative of the range of PHE found in the main set of test soils were subjected to the CISED extraction. In order to categorise the soil host substrates and their PHE distributions across the test materials in a consistent manner, a clustering methodology and associated data visualisation technique as previously used by Wragg [22] and Cox et al. [24] were applied to the SMMR data. Briefly, this involves setting up a data matrix consisting of the percentage element composition ( $\mathrm{Al}, \mathrm{As}, \mathrm{Ca}, \mathrm{Cr}, \mathrm{Fe}$, $\mathrm{K}, \mathrm{Mg}, \mathrm{Mn}, \mathrm{Na}, \mathrm{Ni}, \mathrm{P}, \mathrm{S}, \mathrm{Si}$ ) combined with the amount of material extracted for each substrate $\left(\mathrm{mg} \mathrm{kg}^{-1}\right)$ in each soil for all soils under investigation. The matrix was subjected to hierarchical clustering, where the data were mean centred and scaled with Euclidean distance and linkage using Ward's method. The resulting colourmap was then used to identify chemical composition of the host substrates and the locations at which they were associated.

The $\mathrm{R}$ programming language [25] was used to carry out the $t$-tests used to assess whether the total element and the bioaccessible concentrations of $\mathrm{As}, \mathrm{Cr}$, and $\mathrm{Ni}$ in the soils were significantly different when partitioned by geology and by land use.

2.6. Quality Control. The quality of the XRF and ICPAES analysis and bioaccessibility and CISED extractions was checked according to standard operating procedures 


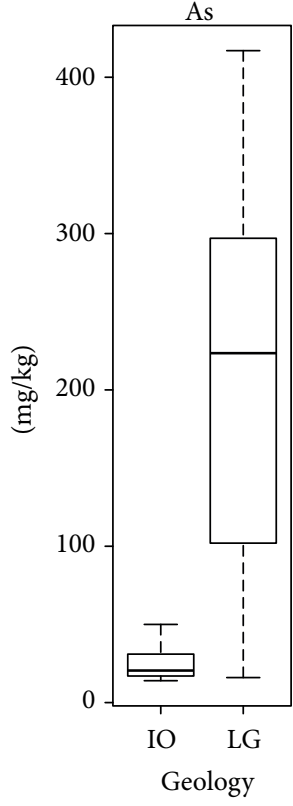

(a)

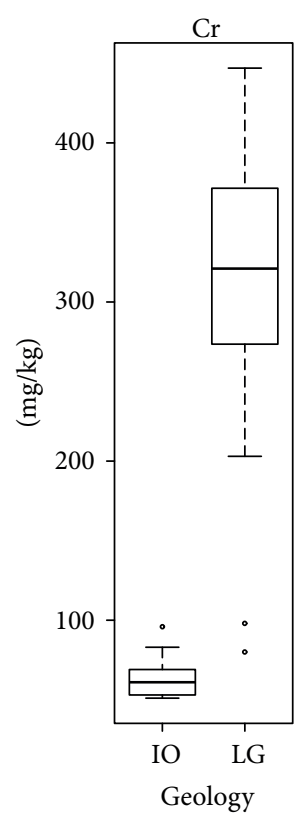

(b)

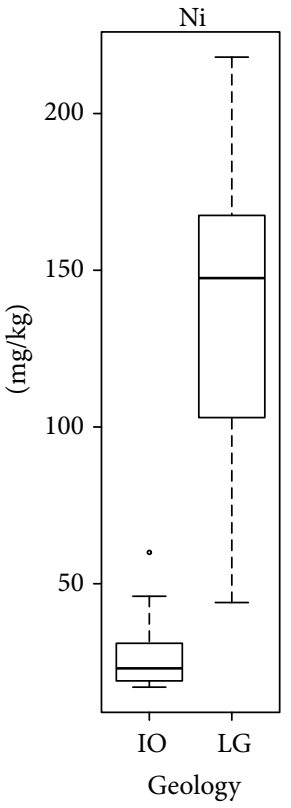

(c)

FIgure 2: Box and Whisker plots for total As, Cr, and Ni concentrations stratified by geology; “IO” represents the Inferior Oolite Group and "LG" represents the Lias Group. The bar shows the median value.

[18]. This included the regular analysis of quality control samples, reference materials, blanks, and extraction and analysis of sample duplicates. For the bioaccessibility testing, the materials that were used as quality control soils are one National Institute of Standards and Technology (NIST) Standard Reference Material (SRM), 2711, and one bioaccessibility guidance soil, BGS 102 . The mean bioaccessibility repeatability for all duplicate extractions was $<10 \%$ for both the stomach and the intestinal phases of the PBET. The bioaccessible values obtained (the highest value obtained for the two phases extracted) for As and $\mathrm{Cr}$ in the BGS 102 reference material [26] ( $n=4)$ were compared against current consensus values for this material generated using the Unified BARGE method (UBM) [26-28], a similar but more complex in vitro bioaccessibility method, developed since the undertaking of this study. Both As and $\mathrm{Cr}$ are in agreement, within error limits, with reported values of $3.77 \pm$ $0.49 \mathrm{mg} \mathrm{kg}^{-1}$ and $9.15 \pm 0.40 \mathrm{mg} \mathrm{kg}^{-1}$ compared to consensus values of $5.38 \pm 2.39 \mathrm{mg} \mathrm{kg}^{-1}$ and $9.60 \pm 2.00 \mathrm{mg} \mathrm{kg}^{-1}$ for As and $\mathrm{Cr}$, respectively. However, there are currently no bioaccessibility values available for Ni. All blank extractions $(n=4)$ returned As, $\mathrm{Cr}$, and Ni values below the limit of quantification for this extraction type.

For the CISED extraction, one sample was extracted in duplicate to assess the extraction repeatability and one blank extraction was carried out to assess any contribution made from the reagent blank. The mean repeatability across the 23 elements analysed was $4.65 \%$. The blank extraction data indicates that the reagent blank did not contribute any elements of interest to the dataset as all results were below the limit of quantification for this extraction type.

\section{Results and Discussion}

3.1. Total PHE Concentrations. Table 1 summarises the geology, lithology, sampling locations, organic matter content, soil $\mathrm{pH}$, and the total and bioaccessible PHE concentrations of the test soils sampled from the Cherwell District. The organic matter content of the test soils ranged between 4.90 and $16.1 \%$ with a range of soil $\mathrm{pHs}$ from 5.83 to 7.54 . The total As, Cr, and Ni ranged from 14.0 to $417 \mathrm{mg} \mathrm{kg}^{-1}$, from 51.0 to $447 \mathrm{mg} \mathrm{kg}^{-1}$, and from 17.0 to $218 \mathrm{mg} \mathrm{kg}^{-1}$, respectively. Mean As, $\mathrm{Cr}$, and $\mathrm{Ni}$ concentrations were 150, 226, and $102 \mathrm{mg} \mathrm{kg}^{-1}$, an order of magnitude above the mean soil concentrations for these PHE reported by the UK soil herbage survey. Figures 2 and 3 are Box and Whisker plots summarizing the total PHE concentrations measured for this study, stratified by underlying geology and land use type, where "IO" and "LG" denote the Inferior Oolite and Lias Groups, respectively, and " $\mathrm{A}$ " and " $R$ " denote allotment and residential, respectively. Figure 2 shows that the total concentrations of each PHE associated with the Lias and inferior Oolite Groups of the underlying geology is significantly different (one way ANOVA $P$ values $<0.001$ for each element); in each case the PHE associated with the Lias group has the highest concentrations. Table 1 summarises the individual samples associated with each geological grouping and identifies Upper and Lower Heyford and Steeple Aston as overlaying the Inferior Oolite with associated comparatively low total $\mathrm{PHE}$ concentrations ranging between 14.0 and $50.0 \mathrm{mg} \mathrm{kg}^{-1}, 51.0$ and $98.0 \mathrm{mg} \mathrm{kg}^{-1}$, and 17.0 and $60.0 \mathrm{mg} \mathrm{kg}^{-1}$ for $\mathrm{As}, \mathrm{Cr}$, and $\mathrm{Ni}$, respectively. In contrast, the total PHE concentrations measured for Drayton, Great Bourton, Shenington, and Wroxton sites (overlaying the Lias 


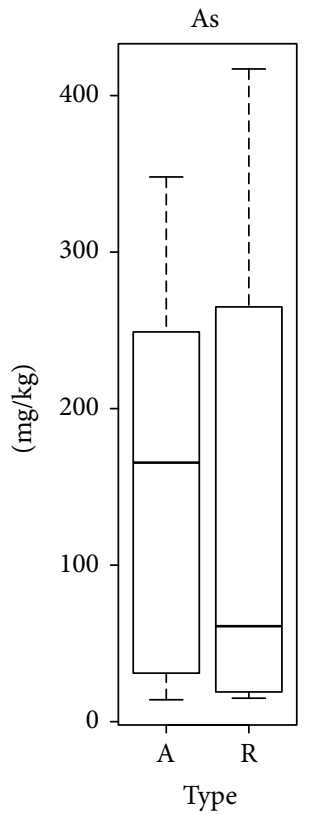

(a)

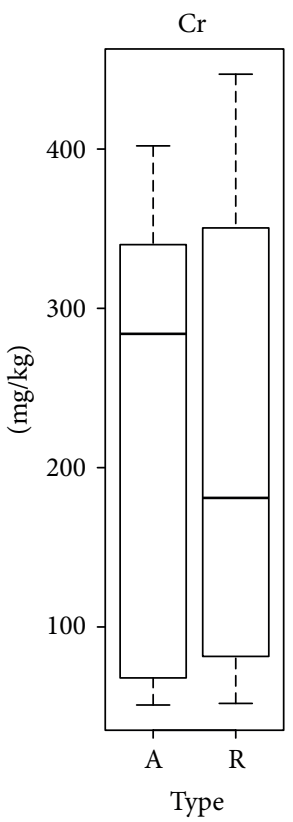

(b)

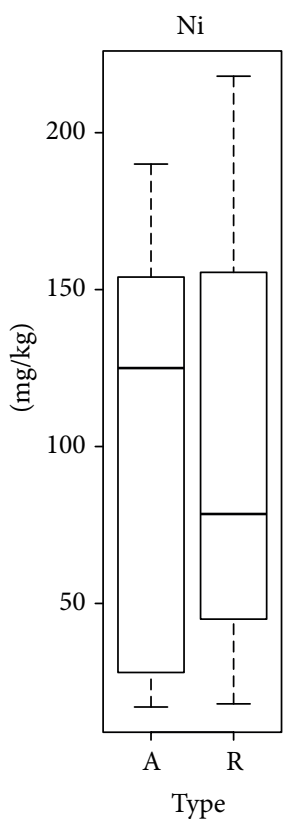

(c)

Figure 3: Box and Whisker plots for total As, Cr, and Ni concentrations stratified by location type; "A" represents allotment land use and "R" represents residential land use. The bar shows the median value.

Group) are higher and have As, Cr, and Ni concentrations ranging from 82.0 to $417 \mathrm{mg} \mathrm{kg}^{-1}$, from 203 to $447 \mathrm{mg} \mathrm{kg}^{-1}$, and from 88.0 to $218 \mathrm{mg} \mathrm{kg}^{-1}$ (Figure 2). Total As, Cr, and Ni concentrations are not significantly different in the soil types when stratified by allotment or residential land use (Figure 3).

The total As concentrations for the Cherwell District are in the same general concentration range of those previously measured by Palumbo-Roe et al. [10] who detected total As concentrations of up to $400 \mathrm{mg} \mathrm{kg}^{-1}$ and by Breward [29] who reported As concentrations of up to $340 \mathrm{mg} \mathrm{kg}^{-1}$ for the Claxby ironstones. However, the As concentrations in ironstone derived soils reported by Nathanail et al., Breward (Frodingham ironstones), and Wragg were markedly lower compared to the ranges reported here [22, 29-31]. Maximum total concentrations in the order of circa $100 \mathrm{mg} \mathrm{kg}^{-1}$ As were reported. In a study by Nathanail et al. [30] on As in Wellingborough allotments, the authors reported a range of total As concentrations between 39.0 and $113 \mathrm{mg} \mathrm{kg}^{-1}$ and a mean of $87.0 \mathrm{mg} \mathrm{kg}^{-1}$. For Cr, Breward [29] reported mean total concentrations of $100 \mathrm{mg} \mathrm{kg}^{-1}$ in topsoils in both the Claxby and Frodingham formations, with ranges of $16.0-254 \mathrm{mg} \mathrm{kg}^{-1}$ and 39.0-250 $\mathrm{mg} \mathrm{kg}^{-1}$, respectively. Wragg [22] reported both total $\mathrm{Cr}$ and $\mathrm{Ni}$ concentrations, in ranges of 66.0$254 \mathrm{mg} \mathrm{kg}^{-1}$ and $20.0-88.0 \mathrm{mg} \mathrm{kg}^{-1}$, respectively. PalumboRoe et al. [10] summarised total $\mathrm{Cr}$ and $\mathrm{Ni}$ concentrations in soils from Scunthorpe, overlaying Jurassic ironstone, as containing $27.0-177 \mathrm{mg} \mathrm{kg}^{-1}$ and $31.0-140 \mathrm{mg} \mathrm{kg}^{-1}$, respectively. Comparison of the total $\mathrm{Cr}\left(51.0-447 \mathrm{mg} \mathrm{kg}^{-1}\right)$ and $\mathrm{Ni}\left(17.0-218 \mathrm{mg} \mathrm{kg}^{-1}\right)$ concentrations from this study shows that the highest total $\mathrm{Cr}$ concentrations measured are greater (circa double) than previously reported [10, 22, 29]. Similarly, the total Ni values determined for the Cherwell District are greater than those previously determined.

3.2. Bioaccessible PHE Concentrations. The PBET method used in this study has, more recently, been superseded by the Unified BARGE Method (UBM) which has been validated for $\mathrm{As}, \mathrm{Cd}$, and $\mathrm{Pb}$ against an animal model [32]. The justifications for using the PBET data for this specific investigation (the UBM had not been fully developed at the time of this study) were twofold as follows.

(i) The PBET test gave As and Cr bioaccessibility values for the BGS102 reference soil that were equivalent, within measurement error, with the consensus values for the reference soil that were determined using the UBM method. In addition, BGS 102 is an ironstone soil from the UK which is very similar in nature to the soil types being measured in Banbury area.

(ii) Recently published work on As bioaccessibility in the UK [33] has also compared the PBET with the UBM for bioaccessibility measurements on soil and found that they give comparable results for As in the UK.

Whilst no validated methods for $\mathrm{Ni}$ and $\mathrm{Cr}$ are available, at the time of writing this paper, the results for bioaccessible $\mathrm{Ni}$ and $\mathrm{Cr}$, as measured by the PBET method, are being used as guidance values for how the bioaccessibility of these two elements is likely to behave.

The choice of which compartment (i.e., gastric or intestine) to report as containing the "bioaccessible fraction" has been discussed widely in the literature $[14,32,34,35]$. The 


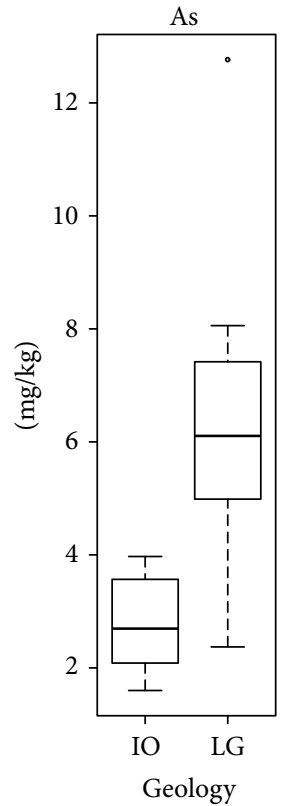

(a)

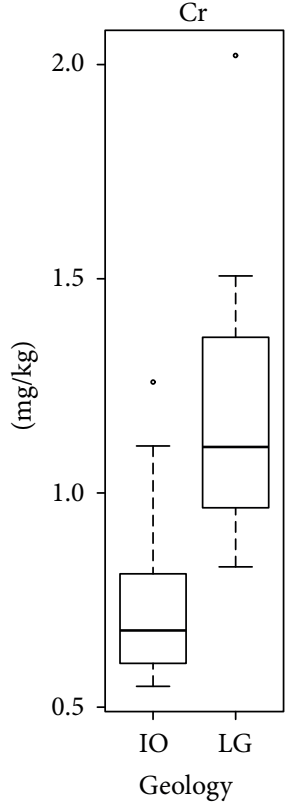

(b)

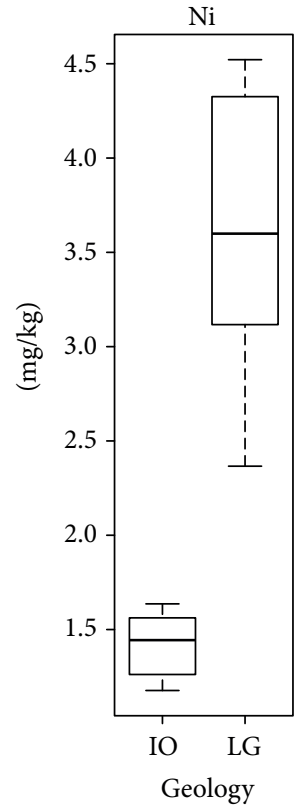

(c)

FIGURE 4: Box and Whisker plots for bioaccessible As, Cr, and Ni stratified by geology; "IO" represents the Inferior Oolite Group and "LG" represents the Lias Group. The bar shows the median value.

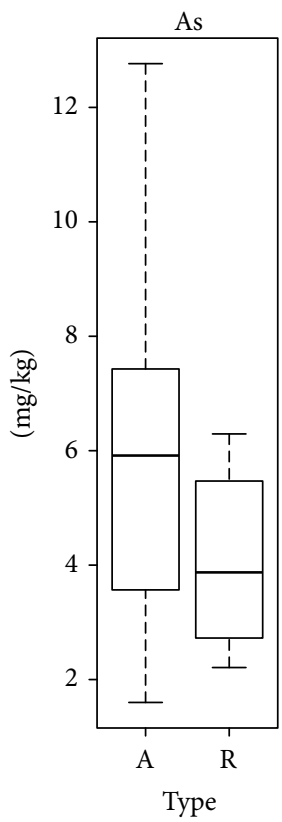

(a)

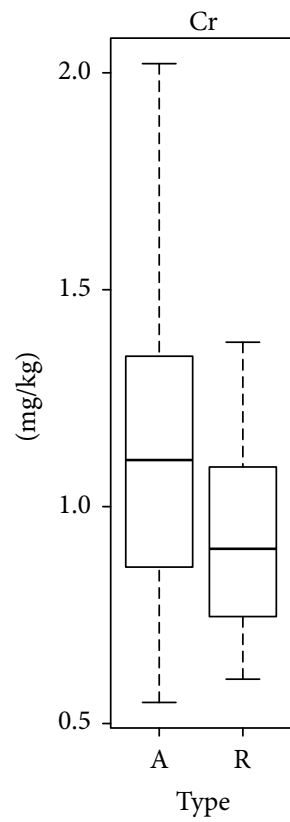

(b)

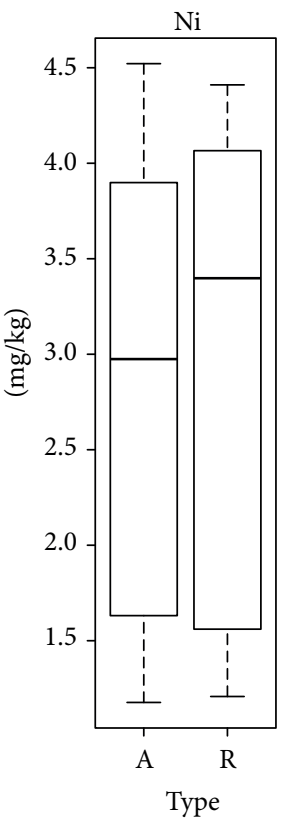

(c)

Figure 5: Box and Whisker plots for bioaccessible As, Cr, and Ni stratified by location type; "A" represents allotment land use and "R" represents residential land use. The bar shows the median value.

general consensus of opinion is that in order to maintain a conservative estimate, the highest value from the available compartments should be used. This approach has been adopted in this study and the following discussion is therefore aimed at a geochemical understanding of this higher amount.
Figures 4 and 5 are Box and Whisker plots summarizing the bioaccessible PHE concentrations, stratified by underlying geology and land use type, respectively. The mean As bioaccessibility obtained from all samples in this study $(n=30)$ was $5.02 \pm 2.48 \mathrm{mg} \mathrm{kg}^{-1}$. Broadly similar mean 
As bioaccessibilities have been reported for ironstone soils by workers, for example, Wragg et al. [11, 22] (mean $3.01 \pm$ $1.37 \mathrm{mg} \mathrm{kg}^{-1} ; n=20$ ), Nathanail et al. [30] (mean $2.95 \pm$ $1.90 \mathrm{mg} \mathrm{kg}^{-1}, n=70$ ), and Palumbo-Roe et al. [10] (mean $\left.3.85 \pm 1.54 \mathrm{mg} \mathrm{kg}^{-1}, n=70\right)$. Figure 4 indicates that, in general, there was a significant difference $(P$ values for all elements <0.001) in the bioaccessible PHE concentrations observed between samples collected from the Inferior Oolite $(n=12)$ and the Lias $(n=18)$, with higher bioaccessible PHE concentrations associated with the Lias Group. Figure 5 shows that differences in land use did not indicate a significant difference in PHE bioaccessibility for any of the PHEs under investigation ( $P$ values for all three elements $>0.05$ ). Cr bioaccessibility for the residential sites only ranged from 0.60 to $1.38 \mathrm{mg} \mathrm{kg}^{-1}$, lower than that measured previously [22], where bioaccessible $\mathrm{Cr}$ was in the range of $1.74-6.00 \mathrm{mg} \mathrm{kg}^{-1}$ for other ironstone derived soils. The Ni bioaccessibility determined for the residential soils collected from the Cherwell District was similar to that determined for the Wellingborough garden soils [22] with ranges of 1.21$4.41 \mathrm{mg} \mathrm{kg}^{-1}$ and $1.59-3.36 \mathrm{mg} \mathrm{kg}^{-1}$, respectively.

3.3. Solid Phase Distribution of PHE. The CISED method has significant advantages over conventional extraction schemes. The use of a nonspecific extraction medium (aqua-regia) and the use of chemometric methods to separate out the different geochemical components significantly reduce the problems associated with the traditional methods which include the following: the nonspecificity of reagents; methods being operationally defined; analytical difficulties associated with the analysis of the extraction reagents; and the long reaction times and associated potential readsorption problems [20, 36]. There are a number of assumptions associated with the CISED test, which include the following.

(i) The relative solubility of the different constituents in the soils by the mineral acid extractant depends not only on the chemical make-up of the component (e.g., $\mathrm{CaCO}_{3}, \mathrm{Fe}_{2} \mathrm{O}_{3}, \mathrm{MnO}$ ) but also on their physical form, for example, their particle size, degree of crystallinity, purity, and so forth. So, for example, crystalline forms of $\mathrm{Fe}_{2} \mathrm{O}_{3}$ may require higher acid strength for dissolution than fine grained $\mathrm{Fe}_{2} \mathrm{O}_{3}$; therefore, the components are defined by both their chemical and physical properties and hence are referred to as physicochemical components. The material under study consists of a mixture of these discrete physicochemical components with distinct major element compositions and the trace metals of interest are distributed amongst these components.

(ii) The physicochemical components will dissolve to different degrees and as the reagent strength increases, each solution will contain differing proportions of each of the components of the test material.

(iii) Within any given physicochemical component, all of the elements are dissolved congruently.

(iv) The CISED method will only identify geochemical components that are soluble in aqua regia.
Whilst the complex mixture of natural soils will not exactly conform to these assumptions, the CISED offers very important improvements over conventional methods. Point (iii) is an assumption that is made in all sequential extraction schemes and has its limitations as it cannot always be guaranteed. For the CISED method, this would not be met for the bulk aluminosilicate minerals of the soil (these do not dissolve well in $\mathrm{HCl} / \mathrm{HNO}_{3}$ mixtures); however, the method is designed to investigate the more reactive surface coatings on the soil particulates, for example, Ca carbonate, Fe oxides, and Mn oxides, where the most mobile forms of the metals are held. These more reactive physicochemical components are well solubilised in the $\mathrm{HCl} / \mathrm{HNO}_{3}$ acid medium and, therefore, the assumption in point (iii) can be taken to be true for the CISED method.

Four of the test samples were subjected to the CISED extraction methodology to determine the physicochemical soil components present across the range of test locations, for example, carbonates, clays, exchangeable phases, and so forth, and the solid phase distribution of $\mathrm{As}, \mathrm{Cr}$, and $\mathrm{Ni}$ between each identified component. Extraction recoveries for the CISED extraction method ranged from 5.71 to $8.43 \%$, from 4.24 to $9.07 \%$, and from 9.32 to $23.1 \%$ for As, Cr, and Ni, respectively. The recovery data alone provides an indication of the mobility of each PHE and shows that Ni is more available to acid extraction (up to 5.0 molar aqua regia) than As or $\mathrm{Cr}$, which are extracted. Application of the SMMR algorithm [37] to the soil extraction data resulted in the determination of a number of physicochemical components for each soil under test. Hierarchical cluster analysis of the mean, centred, and scaled soil extraction data resulted in the production of a colourmap, a visual aid to identify the physicochemical components in the test soils (Figure 6). Each row of Figure 6 represents a physicochemical component found within a given soil; the soil sample is indicated by the first letters which refer to the name codes given in Table 1 and the following element names indicate which elements make up $10 \%$ or more of the physicochemical component composition. The element columns of Figure 6 (right-hand side of the figure) represent the relative amounts of each element present in the component and the E1 to E14 columns represent the relative amounts of the component extracted in each extraction step (increasing acid strength from E1 to E14). Figure 6 indicates the presence of 7 distinct physicochemical clusters ordered in relation to their ease of extractability from the test soils: Organic/Residual pore-water; Fertiliser; Carbonate; Mn oxide; High Carbonate; Al oxide; and $\mathrm{Fe}$ oxide.

Organic/Residual pore-water: the cluster identified as Organic/Residual pore-water was extracted, primarily, during the initial extraction steps of the CISED, steps (1) and (2), using deionised water. This cluster, which was dominated by the presence of $\mathrm{Na}, \mathrm{K}$, and $\mathrm{Si}$, is highly mobile and can be derived from soluble pore-water salts in the soils and possibly soluble humic material which is also water soluble and can contain these elements [38]. This component is associated with three of the four samples under investigation, the allotment and residential samples from Shenington and the allotment sample from Drayton. 


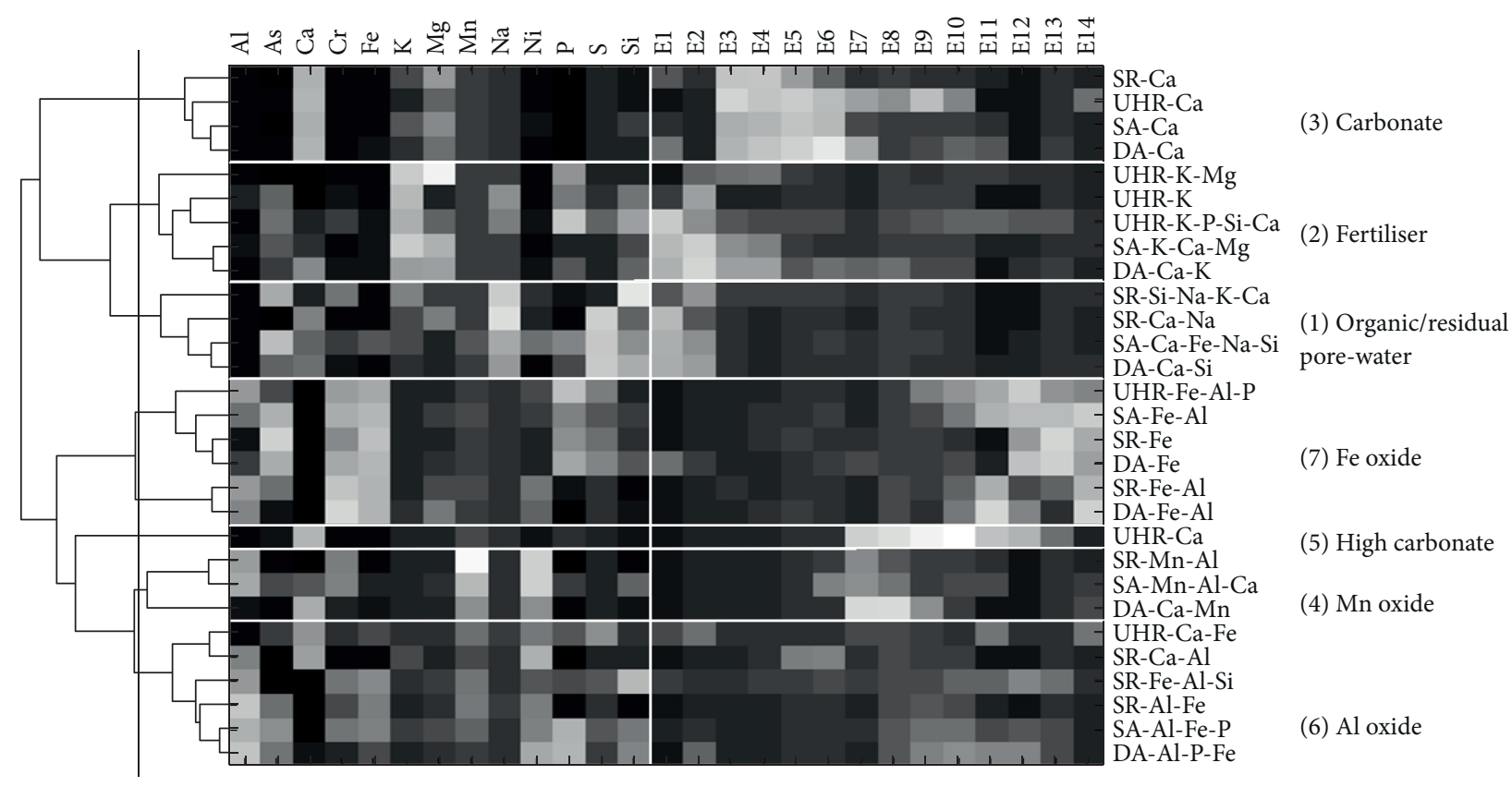

FIGURE 6: Colourmap and associated clustergram for CISED extract data for a selection of the test soils. The dendrogram along the left-hand side shows how individual components link together. The horizontal line divides the colourmap into clusters and the vertical line separates the element compositions data on the left-hand side from the extraction number data on the right. A high proportion of each component and an indication of its composition are shown by a white or pale grey colouration with a low proportion as dark grey or black.

Fertiliser: this cluster was extracted by deionised water predominantly under low acid concentrations $(0.01-0.05 \mathrm{M}$ aqua regia) in a narrow window of extraction and associated with the two allotment samples (Shenington and Drayton) and one of the two residential samples (Upper Heyford). This cluster was dominated by the presence of a number of the primary and secondary plant nutrients used in fertilisers $\mathrm{K}$, $\mathrm{P}$, and $\mathrm{Mg}$, respectively.

Carbonate: a Ca dominated cluster, which also had a contribution from the presence of $\mathrm{Mg}$, was extracted on the first addition of aqua regia and over a relatively narrow window $(0.01-0.05 \mathrm{M})$. This cluster was identified with all samples subjected to the CISED sequential extraction methodology.

Mn oxide: a cluster dominated by the presence of Mn was extracted in a distinct window of extraction, associated with three of the four samples under investigation (Shenington (residential and allotment) and Drayton) and observed at the point where $\mathrm{H}_{2} \mathrm{O}_{2}$ was first added into the test system. It is known that $\mathrm{Mn}$ oxides are readily dissolved in $\mathrm{H}_{2} \mathrm{O}_{2}$ [39], suggesting that this cluster was probably derived from the dissolution of a naturally occurring Mn oxide.

High carbonate: a cluster that was distinctly different from that identified as carbonate was named high carbonate. The differences between the two carbonate clusters were the increased amount of high carbonate identified $\left(7000 \mathrm{mg} \mathrm{kg}^{-1}\right)$, the difference in its composition (Ca only) compared to the carbonate phase, its different window of extraction $(0.10 \mathrm{M}-5.0 \mathrm{M})$, and its association with only one of the test samples (Upper Heyford). This soil component could be associated with the presence of calcite in this individual soil, which has been similarly reported by previous studies of Jurassic ironstones [10,11, 22].

$\mathrm{Al}$ oxide: similarly to the $\mathrm{Mn}$ oxide cluster, a cluster dominated by the presence of $\mathrm{Al}$ is first seen on or around the first addition of $\mathrm{H}_{2} \mathrm{O}_{2}$, a reagent known to aid the dissolution of $\mathrm{Al}$ oxides [39].

Fe oxide: these clusters are most probably derived from relatively pure $\mathrm{Fe}$ oxides, because of their high $\mathrm{Fe}$ contents and because high acid concentrations are required to extract them from the soils [40]. All soils under investigation are associated with this cluster, which is extracted at medium to high acid concentrations ( $0.50-5.0 \mathrm{M}$ aqua regia) and over a broad window of extraction.

3.4. Relationship between Distribution of PHEs and Bioaccessibility. The CISED procedure has now identified the main easily extractable physicochemical components in the soils and the algorithm also gives the amount of each PHE associated with these components. In a similar manner to previous studies [11, 24, 36], the bioaccessibility of the PHE of interest has been related to the distribution of the PHE in the individual test soils subjected to the CISED in order to gain an understanding about the sources of contaminant bioaccessibility. Figure 7 summarises the results showing the cumulative amount of each PHE extracted going from the most easily extracted to those only extracted at higher acid concentration with the bioaccessible fraction marked as a horizontal dashed line (the total concentration of each metal is also noted on each plot but not shown graphically as these values are very much higher than the bioaccessible 


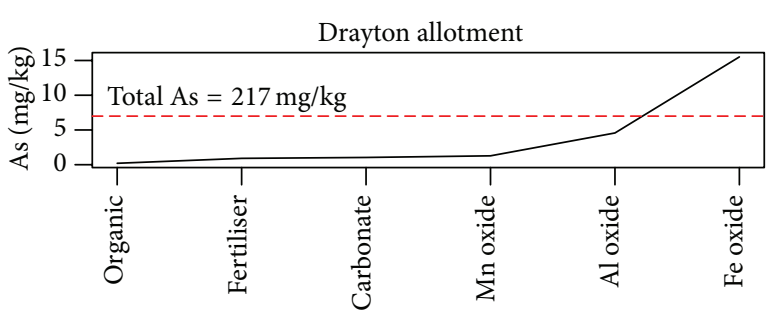

(a)

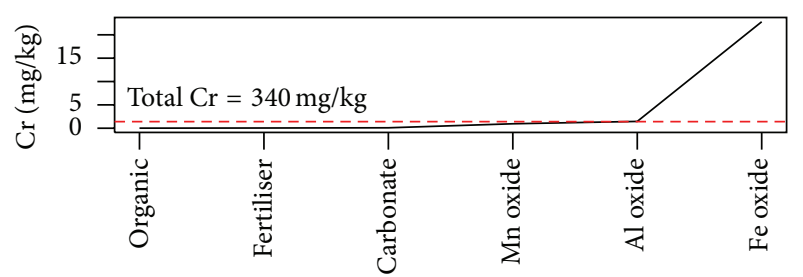

(c)

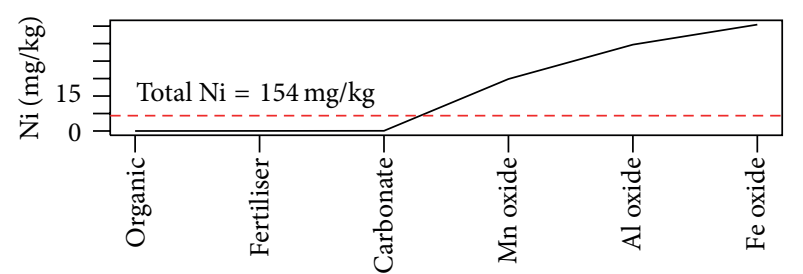

(e)

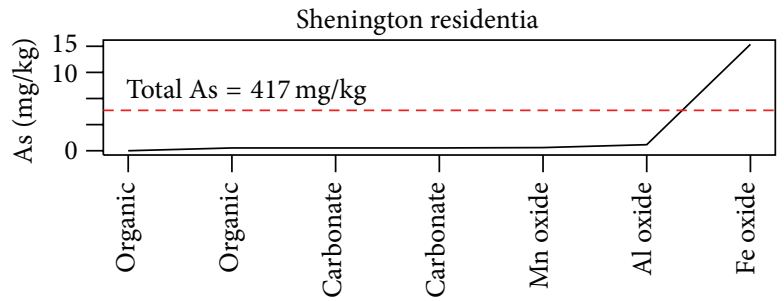

(g)

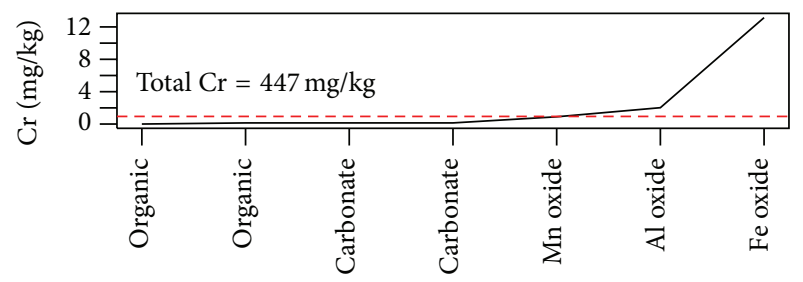

(i)

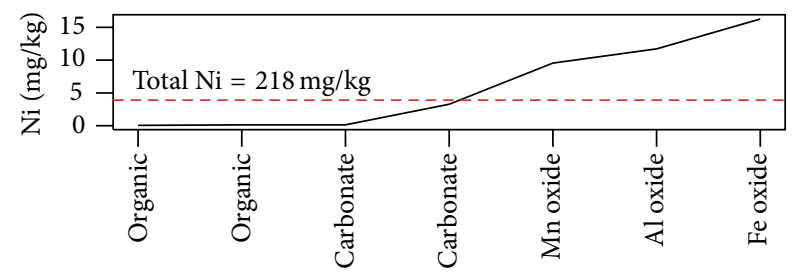

(k)

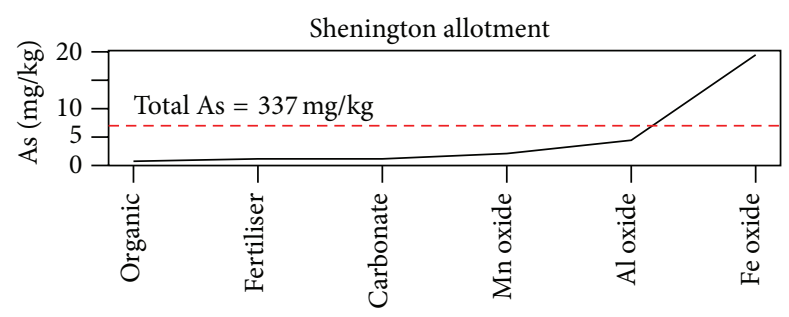

(b)

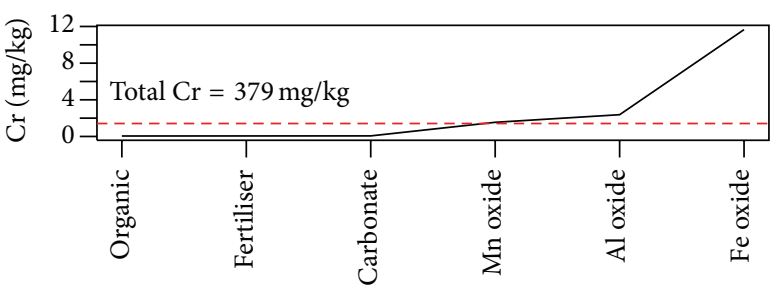

(d)

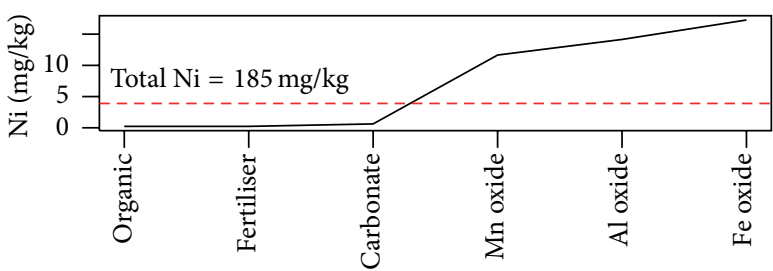

(f)

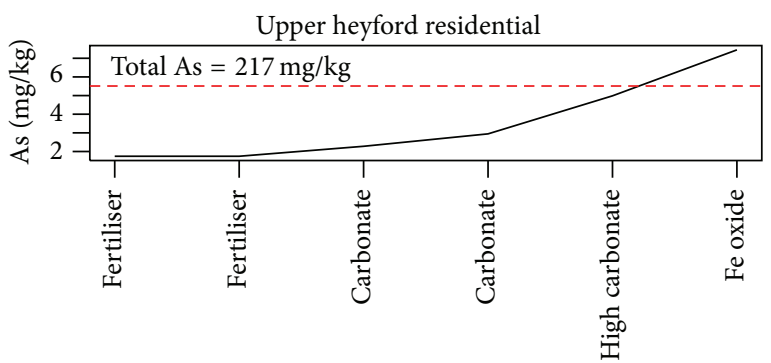

(h)

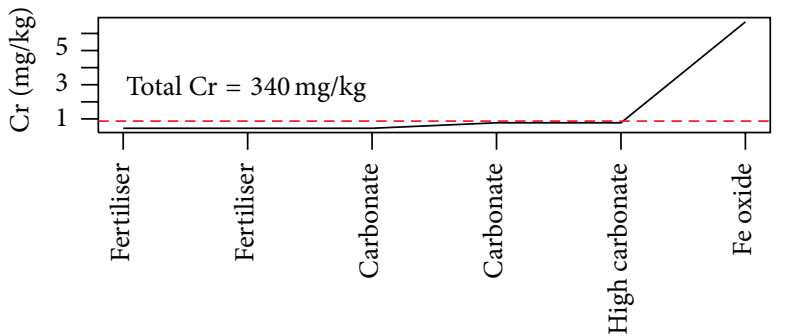

(j)

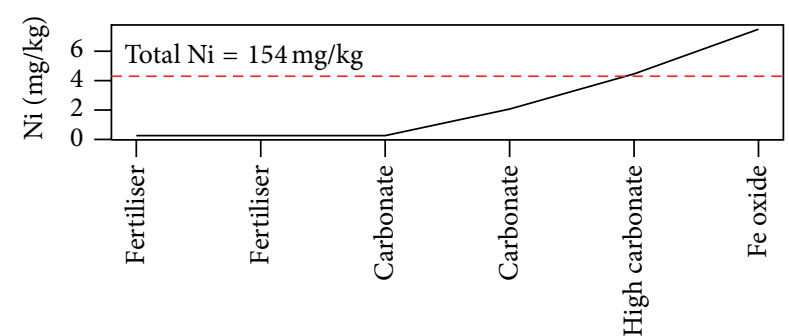

(l)

FIGURE 7: Comparisons of the cumulative mass of As, Cr, and Ni extracted in the CISED identified physicochemical components and its relationship to the bioaccessible fractions. Solid line represents the cumulative mass extracted; the dashed line represents the bioaccessible fraction. Total concentrations of elements are noted on the plot. 
and CISED extracted values). In Figure 7, the cumulative amount of PHE extracted up to the point at which the bioaccessibility line intersects the cumulative mass extracted indicates which physic-chemical components are likely to be associated with the bioaccessible fraction of the PHE. Examination of Figure 7 shows that each element follows the same relationship between cumulative mass extracted and the bioaccessible fraction in each sample:

(i) for As, the bioaccessible fraction comes from the organic, fertiliser, carbonate, $\mathrm{Mn}$ oxide, and $\mathrm{Al}$ oxide fractions with some partial dissolution of the Fe oxide;

(ii) for $\mathrm{Cr}$, the bioaccessible fraction comes from the organic, fertiliser, carbonate, $\mathrm{Mn}$ oxide, and $\mathrm{Al}$ oxide fractions but not from the Fe oxide fraction;

(iii) for $\mathrm{Ni}$, the bioaccessible fraction comes almost exclusively from the carbonate fraction.

\section{Conclusions}

A combination of total element analysis, bioaccessibility measurements, and sequential extraction has proved to be a powerful combination of techniques to understand the mobility of PHE in soils derived from Jurassic ironstone in the UK. Whilst the total concentration of As, Cr, and $\mathrm{Ni}$ is elevated due to the soil parent material, bioaccessibility testing, which mimics the conditions in the human gastrointestinal system, shows that only a small proportion of the total concentration is available for absorption into the human body. The CISED test shows that the nonmobile forms of the PHEs are strongly sorbed to iron oxides and are unreactive. The study also shows how parent material geology has a significant effect on the total element concentrations and the bioaccessibility of PHE. Land use (allotment versus residential) does not show such a large effect but the allotment bioaccessibility data show a bigger spread and possibly higher values for As and $\mathrm{Cr}$ which may be due to cultivation practices such as addition of fertilisers and organic matter.

\section{Conflict of Interests}

The authors declare that there is no conflict of interests regarding the publication of this paper.

\section{Acknowledgments}

This paper is published with the permission of the Executive Director of the British Geological Survey (Natural Environment Research Council). The contribution of all BGS staff involved in the collection and analysis of the samples is gratefully acknowledged.

\section{References}

[1] Environment Agency, Human Health Toxicological Assessment of Contaminants in Soil, Environment Agency (England and Wales), Bristol, UK, 2009.
[2] C. P. Nathanail, C. McCaffrey, M. R. Ashmore et al., The LQM/CIEH Generic Assessment Criteria for Human Health Risk Assessment, Land Quality Press, Nottingham, UK, 2009.

[3] A. Kabata-Pendias and A. B. Mukherjee, Trace Elements From Soil to Human, Springer, Berlin, Germany, 2007.

[4] P. L. Smedley and D. G. Kinniburgh, "A review of the source, behaviour and distribution of arsenic in natural waters," Applied Geochemistry, vol. 17, no. 5, pp. 517-568, 2002.

[5] B. G. Rawlins, S. P. McGrath, A. J. Scheib et al., The Advanced Soil Geochemical Atlas of England and Wales, British Geological Survey, Nottingham, UK, 2012.

[6] S. P. McGrath, "Nickel," in Heavy Metals in Soils, B. J. Alloway, Ed., Blackie Academic \& Professional, London, UK, 1995.

[7] E. L. Ander, C. C. Johnson, M. R. Cave, B. Palumbo-Roe, C. P. Nathanail, and R. M. Lark, "Methodology for the determination of normal background concentrations of contaminants in English soil," Science of the Total Environment, vol. 454-455, pp. 604-618, 2013.

[8] M. Cave, H. Taylor, and J. Wragg, "Estimation of the bioaccessible arsenic fraction in soils using near infrared spectroscopy," Journal of Environmental Science and Health A, vol. 42, no. 9, pp. 1293-1301, 2007.

[9] M. R. Cave, J. Wragg, B. Palumbo, and B. A. Klinck, Measurement of the Bioaccessibility of Arsenic in UK Soils, Environment Agency, 2003.

[10] B. Palumbo-Roe, M. R. Cave, B. A. Klinck et al., "Bioaccessibility of arsenic in soils developed over Jurassic ironstones in eastern England," Environmental Geochemistry and Health, vol. 27, no. 2, pp. 121-130, 2005.

[11] J. Wragg, M. Cave, and P. Nathanail, "A study of the relationship between arsenic bioaccessibility and its solid-phase distribution in soils from Wellingborough, UK," Journal of Environmental Science and Health A, vol. 42, no. 9, pp. 1303-1315, 2007.

[12] M. R. Cave, J. Wragg, and H. Harrison, "Measurement modelling and mapping of arsenic bioaccessibility in Northampton, UK," Journal of Environmental Science \& Health Part A, vol. 48, pp. 629-640, 2013.

[13] D. J. Paustenbach, "The practice of exposure assessment: a state-of-the-art review (Reprinted from Principles and Methods of Toxicology, 4th edition, 2001)," Journal of Toxicology and Environmental Health B, vol. 3, pp. 179-291, 2000.

[14] C. P. Nathanail and R. Smith, "Incorporating bioaccessibility in detailed quantitative human health risk assessments," Journal of Environmental Science and Health A, vol. 42, no. 9, pp. 11931202, 2007.

[15] J. H. Taylor, Petrology of the Northampton Sand and Ironstone Formation, Memoirs of the Geological Survey of Great Britain, 1949.

[16] C. C. Johnson, N. Breward, E. L. Ander, and L. Ault, "G-BASE: baseline geochemical mapping of Great Britain and Northern Ireland," Geochemistry, vol. 5, no. 4, pp. 347-357, 2005.

[17] M. J. Duggan, M. J. Inskip, S. A. Rundle, and J. S. Moorcroft, "Lead in playground dust and on the hands of schoolchildren," Science of the Total Environment, vol. 44, no. 1, pp. 65-79, 1985.

[18] M. N. Ingham and B. A. R. Vrebos, "High productivity geochemical XRF analysis," Advances in X-Ray Analysis, vol. 37, pp. 717-724, 1994.

[19] M. V. Ruby, A. Davis, R. Schoof, S. Eberle, and C. M. Sellstone, "Estimation of lead and arsenic bioavailability using a physiologically based extraction test," Environmental Science and Technology, vol. 30, no. 2, pp. 422-430, 1996. 
[20] M. R. Cave, A. E. Milodowski, and E. N. Friel, "Evaluation of a method for identification of host physico-chemical phases for trace metals and measurement of their solid-phase partitioning in soil samples by nitric acid extraction and chemometric mixture resolution," Geochemistry, vol. 4, no. 1, pp. 71-86, 2004.

[21] M. R. Cave and J. Wragg, Determination of Major and Trace Cations in Aqueous Samples by Inductively Coupled Plasma Atomic Emission Spectrometry (Varian/Vista), British Geological Survey, 2002.

[22] J. Wragg, A Study of the Relationship Between Arsenic Bioaccessibility and Its Solid Phase Distribution in Wellingborough Soils, Geography, Nottingham, Nottingham, UK, 2005.

[23] M. R. Cave, The Use of Self Modelling Mixture Resolution for the Interpretation of Geochemical Data, British Geological Survey, 2009.

[24] S. Cox, M. M. Chelliah, J. McKinley et al., "The importance of solid-phase distribution on the oral bioaccessibility of $\mathrm{Ni}$ and Cr in soils overlying Palaeogene basalt lavas, Northern Ireland," Environmental Geochemistry and Health, vol. 35, no. 5, pp. 553567, 2013.

[25] R. R. Development Core Team, A Language and Environment for Statistical Computing, R Foundation for Statistical Computing, Vienna, Austria, 2011.

[26] J. Wragg, BGS Guidance Material 102, Ironstone Soil, Certificate of Analysis, British Geological Survey, 2009.

[27] A. Broadway, M. R. Cave, J. Wragg et al., "Determination of the bioaccessibility of chromium in Glasgow soil and the implications for human health risk assessment," Science of the Total Environment, vol. 409, no. 2, pp. 267-277, 2010.

[28] J. Wragg, M. Cave, N. Basta et al., "An inter-laboratory trial of the unified BARGE bioaccessibility method for arsenic, cadmium and lead in soil," Science of the Total Environment, vol. 409, no. 19, pp. 4016-4030, 2011.

[29] N. Breward, "Arsenic and presumed resistate trace element geochemistry of the Lincolnshire (UK) sedimentary ironstones, as revealed by a regional geochemical survey using soil, water and stream sediment sampling," Applied Geochemistry, vol. 22, no. 9, pp. 1970-1993, 2007.

[30] P. Nathanail, C. McCaffrey, R. Ogden, N. Foster, A. Gillett, and D. Haynes, "Uptake of arsenic by vegetables for human consumption: a study of Wellingborough allotment plots," Land Contamination and Reclamation, vol. 12, no. 3, pp. 219-238, 2004.

[31] J. Wragg and B. Klinck, "The bioaccessibility of lead from Welsh mine waste using a respiratory uptake test," Journal of Environmental Science and Health A, vol. 42, no. 9, pp. 12231231, 2007.

[32] S. Denys, J. Caboche, K. Tack et al., "In Vivo validation of the unified barge method to assess the bioaccessibility of arsenic, antimony, cadmium, and lead in soils," Environmental Science \& Technology, vol. 46, pp. 6252-6260, 2012.

[33] J. D. Appleton, M. R. Cave, and J. Wragg, "Anthropogenic and geogenic impacts on arsenic bioaccessibility in UK topsoils," Science of the Total Environment, vol. 435-436, pp. 21-29, 2012.

[34] J. Wragg and M. R. Cave, Methods for the Measurement of the Oral Bioaccessibility of Selected Metals and Metalloids in Soils: A Critical Review, Environment Agency, 2003.

[35] J. Wragg, M. R. Cave, H. Taylor et al., Inter-Laboratory Trial of a Unified Bioaccessibility Procedure, British Geological Survey, 2009.
[36] J. Wragg and M. Cave, "Assessment of a geochemical extraction procedure to determine the solid phase fractionation and bioaccessibility of potentially harmful elements in soils: a case study using the NIST 2710 reference soil," Analytica Chimica Acta, vol. 722, pp. 43-54, 2012.

[37] M. Cave, The Use of Self Modelling Mixture Resolution Methods for the Interpretation of Geochemical Data Sets, British Geological Survey, 2008.

[38] R. Santamaría-Fernández, M. R. Cave, and S. J. Hill, “The effect of humic acids on the sequential extraction of metals in soils and sediments using ICP-AES and chemometric analysis," Journal of Environmental Monitoring, vol. 5, no. 6, pp. 929-934, 2003.

[39] J. R. Clark, "Enzyme-induced leaching of B-horizon soils for mineral exploration in areas of glacial overburden," Transactions of the American Institute of Mining, Metallurgical B, vol. 102, pp. B19-B29, 1993.

[40] R. M. Cornell and U. Schwertmann, The Iron Oxides-Structure Properties, Reactions, Occurences and Uses, VCH Publishers, Weinheim, Germany, 1996. 

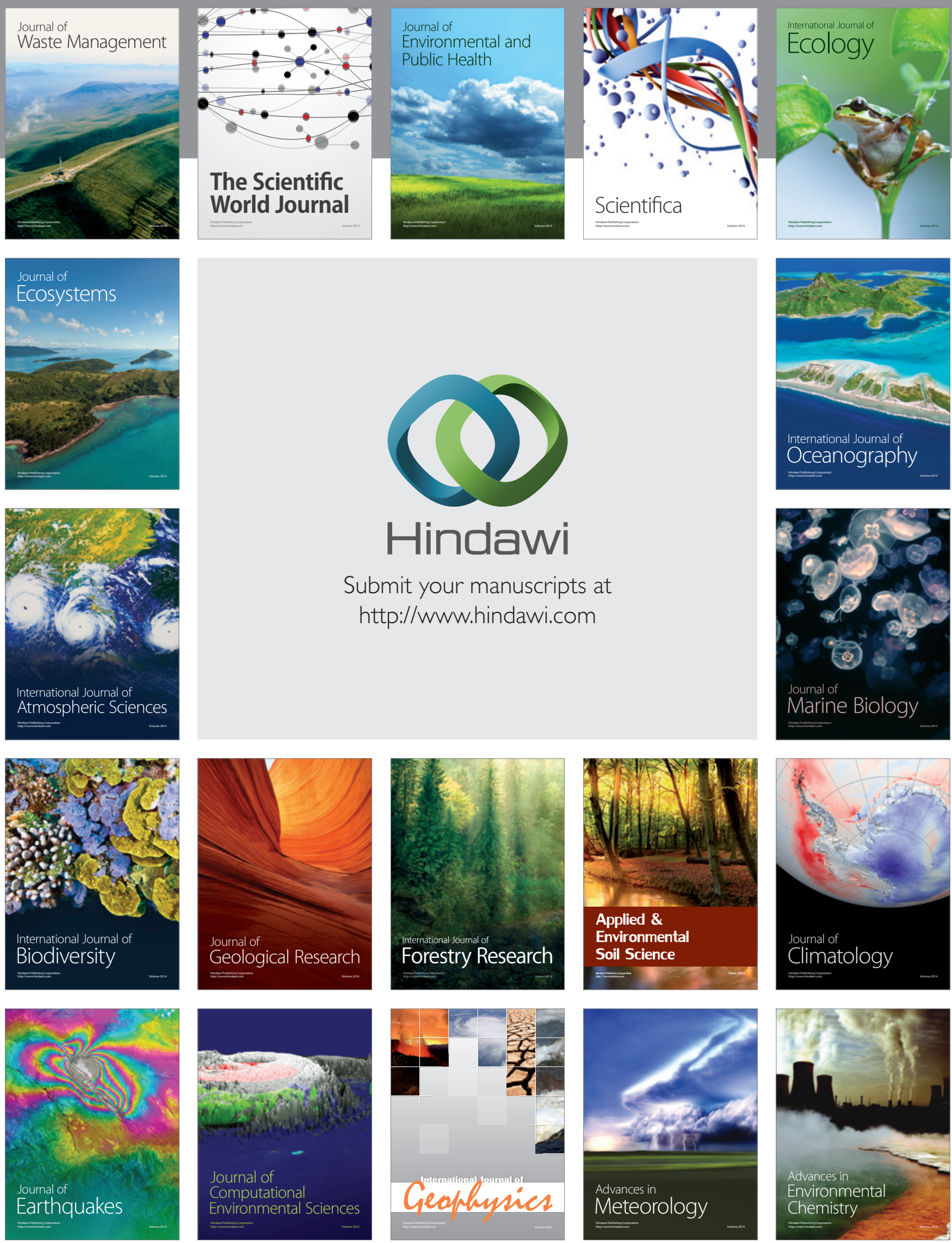